Naamsestraat 61 - bus 3550 B-3000 Leuven - BELGIUM

Tel : 32-16-326661 vives@econ.kuleuven.be

\title{
Globalisation, concentration and footloose firms: in search of the main cause of the declining labour share
}

Forthcoming in the Review of World Economics

John Hutchinson

Damiaan Persyn

Copyright @ 2010 by K.U.LEUVEN, VIVES. Discussion papers are in draft form. This discussion paper is distributed for purposes of comment and discussion only. It may not be reproduced without permission of the copyright holder. 


\title{
Globalisation, concentration and footloose firms: in search of the main cause of the declining labour share ${ }^{\text {th }}$
}

\author{
John Hutchinson $^{\mathrm{a}}$, Damiaan Persyn ${ }^{\mathrm{b}}$ \\ ${ }^{a}$ European Central Bank Kaiserstrasse 29, D-60311 Frankfurt am Main, Germany \\ ${ }^{b}$ VIVES and LICOS Faculty of Business and Economics, Catholic University of Leuven \\ Naamsestraat 61, B-3000 Leuven, Belgium tel: +3216324230
}

\begin{abstract}
Over the last two decades the share of national income which accrues to labour has followed a marked downward trend across a host of industrialised countries. This paper reassesses the relative importance of several potential causes of this phenomenon. Overall, the findings suggest that lower trade costs and factors often associated with economic integration such as international low-wage competition and industry concentration have contributed to the decline in the labour share. However, their effects have been limited when compared to the effects of skill-based technological change and cyclical price changes of intermediary goods.
\end{abstract}

\section{Introduction}

The debate on how to divide national income among capital owners and labour periodically reignites between policy makers, politicians, trade unions and the popular press. Recent interest in factor shares stems from the fact that over the last two decades, the labour share across a host of industrialised countries has followed a downward trend, as opposed to the periods in the 1960s and 1970s where the labour share of national income was considerably higher.

Figure 1 shows the evolution of the labour share for the EU as a whole (left panel) and some large member states (right panel). The graphs clearly show why the evolution of the

\footnotetext{
This work is based on Hutchinson and Persyn (2009). The authors would like to thank Iaonni Ganoulis, Joep Konings, Hylke Vandenbussche, Luc Lauwers, Peter Neary, Maarten Goos, Vincent Labhard, Aidan Meyler, Fabrice Orlandi, Moreno Roma and Rolf Strauch for their helpful comments and suggestions. The opinions are those of the authors and do not reflect those of the European Central Bank or Eurosystem

Email addresses: john. hutchinson@ecb. int (John Hutchinson), damiaan.persyn@econ.kuleuven.be (Damiaan Persyn)
} 

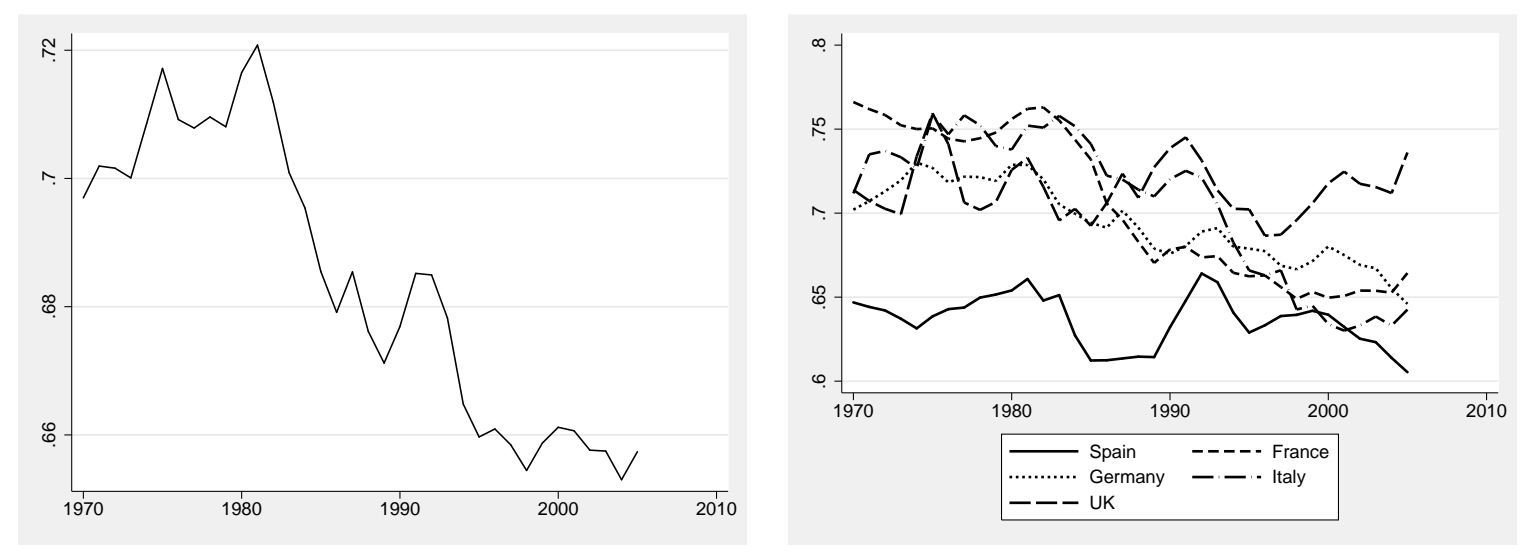

Figure 1: The evolution of the labour share in the EU15. 1970-2005. Source: EUKLEMS

labour share has drawn much attention recently: whereas the labour share was at a high level and even increasing in the 1970s, this was followed by a significant decrease in the subsequent decades. In the later years the downward trend seems to have bottomed out. The evolution of the labour share has been rather similar within most large EU member states over the same time period.

While early studies assumed factor share constancy as one of the key regularities characterising economic growth (e.g., Kaldor (1963)), subsequent contributions have shown that factor shares have not been stable in the medium-term with several explanations being proposed (Blanchard, 1997; De Serres, Scarpetta, and De La Maisonneuve, 2001; Bentolila and Saint-Paul, 2003; Jaumotte and Tytell, 2007; Guscina, 2007; Meyler, 2001). Overall, no single theory or specific cause is able to explain all changes in factor shares. What does appear to emerge, however, is that explanations can essentially be grouped into temporary and cyclical factors such as energy price shocks and adjustment costs, while others can be viewed as being more structural in nature.

This paper re-examines the possible factors which can explain the observed decline in the labour share and their relative importance. The structural factors affecting factor shares considered in this paper include changes in the sectoral composition of economies, (skillbiased) technological change, firm's product market power and foreign competition. Several of 
these factors may have been influenced by increasing economic integration in general and in particular, by the European integration process in particular.

Within the EU the Single Market programme, several waves of enlargement, and the introduction of the euro have all contributed to increasing European economic integration over the last few decades. Previous studies examining the impact of globalisation on the labour share tend to focus on the increasing role of emerging economies such as China and India in world trade (e.g. Jaumotte and Tytell, 2007; Guscina, 2007). Nevertheless, intra-EU trade accounts for approximately two thirds of all EU trade ${ }^{1}$, and the period during which the decline in the labour share took place in most EU countries (early eighties to late nineties) corresponds to a period of intensive intra-EU trade liberalisation. This study therefore concentrates on the European integration process and examines how declining intra-EU trade costs impacted on the share of labour in national income.

The legacy of obstacles to trade in the EU and their subsequent dismantling have had considerable implications on the European industrial structure (cfr. Lyons, Matraves, and Moffatt, 2001). While it is widely accepted that efficiency and welfare benefits emerge as a result of increased competition in product markets, European countries have been considerably slower in adopting anti-trust legislation when compared to the US (Mueller, 1996). In the founding Treaty of the European Community, despite incorporating strict anti-trust rules, the emphasis was on cross-border implications and not on within country competition. It was not until the Maastricht Treaty that antitrust legislation in certain countries converged closer to European standards. Moreover, firms are ever more adept at employing innovative strategies in order to ensure that any rents earned are protected from strict regulation (Konings, Van Cayseele, and Warzynski, 2001). Consequently, it would appear to be of interest to examine whether the market structure developments which occurred concurrently with the integration process in the EU have affected the labour share in Member States.

\footnotetext{
${ }^{1}$ External and intra-European Union trade. Statistical Yearbook 2008.
} 
An additional channel through which the process of European economic integration might affect the labour share is through the increased mobility of firms. As firms become ever more footloose, Member States increasingly compete with each other as a means of attracting foreign direct investment. Therefore, whether increasing international competition contributes to the decreasing labour share is also examined.

Moreover, economic integration may have caused various changes in technology and factor markets, or may have happened concurrently with these. Some examples are the steady increase in the relative supply of skilled workers which has been observed in developed countries, technological innovations and capital accumulation leading to increased demand for capital-complementary skilled labour (Monfort, Vandenbussche, and Forlani, 2008), and shocks to prices of intermediary goods. These trends coincided with a general increase in the openness to trade, and we will attempt to determine to what extend the observed decline in the labour share can be attributed to each of these factors.

To do this, we build on the work of Bentolila and Saint-Paul (2003) (BS). These authors estimate the impact of changing technology, factor prices, adjustment costs and the bargaining power of unions on the labour share. In order to investigate how European economic integration affects the labour share, this study extends their model and estimates the impact of declining trade costs, foreign competition, changes in market structure, skill-biased technological change and capital accumulation. Although the empirical analysis of this paper focuses on European economic integration, the theoretical framework applies equally well to global economic integration. Since European economic integration was already well under way when trade integration with low-wage countries started to strengthen, it may shed some light on possible future effects of closer integration at a global scale.

A significant contribution of this paper stems from enhancing the measurement of factors explaining the labour share. For example, previous studies examining the impact of globalisation on factor shares use aggregated measures of trade openness such as the ratio of trade to 
GDP (Guscina, 2007; Moral and Gernre, 2007), while this study uses bilateral trade data at the industry level to construct a measure of trade openness which is derived directly from theory. In addition, the role of market structure is estimated by using mark-ups and concentration ratios derived from firm-level data, which have not been examined empirically in previous studies.

\section{Globalisation and the labour share}

\subsection{The evolution of trade openness}

Globalisation is often seen as a possible cause of the declining share of labour in national income. A prediction of the classic Heckscher-Ohlin model of international trade is that the reward to labour in relatively capital intensive countries (such as the countries under consideration) declines after opening up to trade. More recent models of union wage demands with footloose firms predict that when firms become more footloose, they might be able to limit union wage demands by threatening to relocate. Globalisation may also affect the average size of firms (or the entire firm size distribution), and the fashion or intensity of competition between firms. Larger footloose firms with more market power may be expected to pay out a smaller share of their value added to employees. To investigate the aggregate effect of globalisation through such channels, the measure of trade openness as derived by Head and Ries (2001), is calculated using bilateral trade data at the industry level from the CEPII Trade and Productivity database. Head and Ries (2001) show that under reasonable assumptions a measure $\phi$ of the 'freeness of trade' can be calculated, which is inversely related to trade costs, using data on the value of the trade flow of industry $k$ from country $i$ to country $j$ in year $t$, which is denoted by $I_{i j k t}$; and data on local production minus exports, which can be understood as 'exports to self' denoted by $I_{i i k t}$. Head and Ries (2001) derive the following 


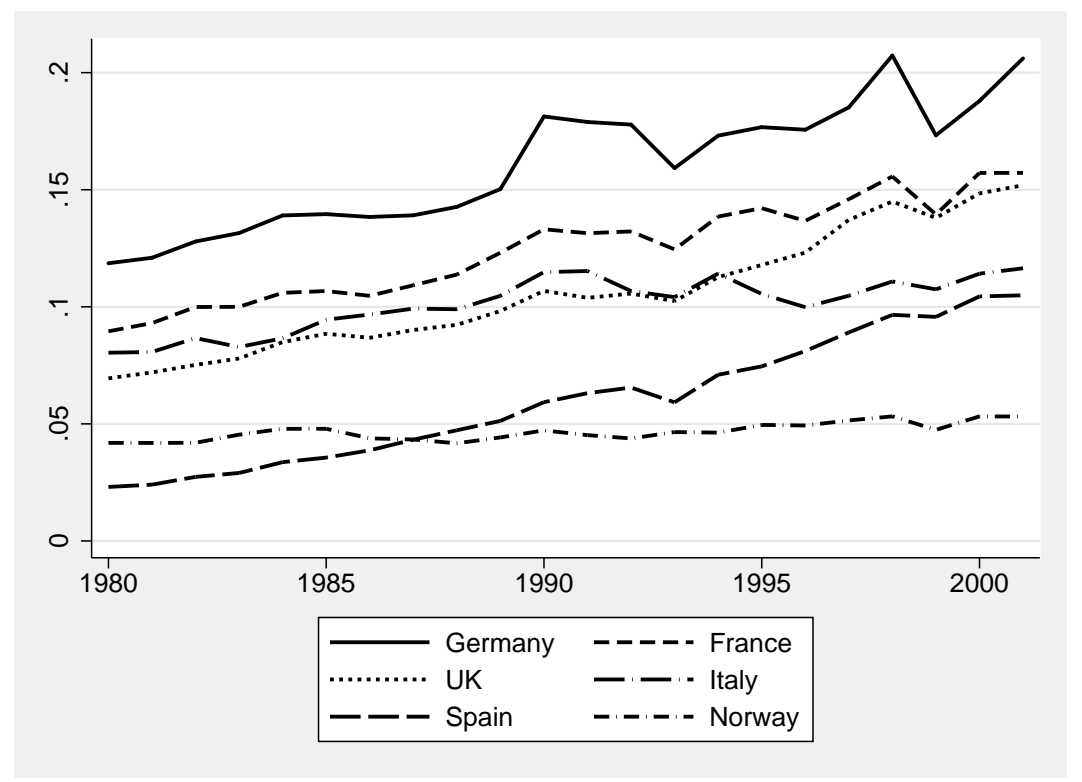

Figure 2: The evolution of trade openness with respect to the EU

expression for $\phi$ which does not depend on, for example, prices and wages

$$
\phi_{i j k t}=\sqrt{\frac{I_{i j k t} I_{j i k t}}{I_{i i k t} I_{j j k t}}} .
$$

The value of $\phi_{i j k t}$ ranges from 0 to 1 , with 0 indicating prohibitive trade costs and 1 costless trade. Figure 2 illustrates the evolution of trade openness $\phi$ with respect to the EU15 for a selection of large member states plus Norway $^{2}$, for the period 1980-2003, calculated using trade flow data from Mayer, Paillacar, and Zignago (2008). What transpires is that the degree of trade openness increased significantly over this period. Spain became much more integrated following its accession to the EU in 1986. Norway did not experience the large increase of trade openness with respect to the EU such as Spain and the other member states did, which suggests that the European integration process was the main driver behind the intra-EU decline in trade costs. The fact that the decline in the labour share occurred concurrently with this significant decline in trade costs, makes it suggestive to draw conclusions about a causal relationship. The

\footnotetext{
${ }^{2}$ Trade data is not available for Ireland, Greece, Luxembourg, Slovenia and Cyprus.
} 
fact that we observe both the labour share and the measure for trade openness over many years, for different countries, and for different industries, will allow us to investigate this hypothesis in a more formal framework in section 4, where we will also be able to control for other factors affecting the labour share.

\subsection{Globalisation and market structure}

For some, globalisation brings the image of large multinationals, who by their sheer market power are able to exploit the local workforce, or at least are able to limit the bargaining power of labour unions. In this section we briefly consider whether increasing economic integration indeed has been accompanied by increasing concentration and higher mark-ups for firms.

For this analysis we draw on the reported company accounts of European manufacturing firms from the AMADEUS database. This commercial database is collected by Bureau Van $\mathrm{Dijk}^{3}$. The data is based on a standardised format of company accounts with the data covering balance sheet, and profit and loss variables. The information contained in this dataset allows to calculate concentration measures $c_{k}$, which express the proportion of the industry's output accounted for by the $k$ largest firms. ${ }^{4}$ To estimate the market power of firms the Lerner index $m=(p-\mu) / p$ was estimated using the method of Hall (1988). $m$ is a measure of the mark-up of prices $p$ over marginal costs $\mu$. Table 1 shows the evolution of $c_{k}$, the market share of the largest $k$ firms in each sector and country, and the estimate of the mark-up $m$ together with the evolution of the Herfindahl-Hirsch index $h$. The reported estimates were obtained from merging different versions of the AMADEUS dataset spanning the period 1991-2005, retaining information for 13 manufacturing sectors, for all EU15 member states except Luxembourg, and averaging the sector-country level $c_{j}$ and $m$ measures over all countries and sectors. Table 1 reveals some remarkable facts about the evolution of market concentration in the EU15 over

\footnotetext{
${ }^{3}$ Previous papers to use the Amadeus dataset include Huizinga and Laeven (2007); Klapper, Laeven, and Rajan (2006); Budd, Konings, and Slaughter (2005).

${ }^{4}$ Or more formally, $c_{k}=\sum_{i=1}^{k} s_{i} / \sum_{i=1}^{n} s_{i}$, with $s_{i}$ the sales of firm $i$. Firms have been sorted by sales such that $s_{i}>s_{i+1}$ and $n$ is the total number of firms in the industry under consideration.
} 


\begin{tabular}{cccccccccc}
\hline year & $c_{1}$ & $c_{2}$ & $c_{4}$ & $c_{8}$ & $c_{16}$ & $c_{32}$ & $c_{64}$ & $h$ & $m$ \\
\hline 1991 & 0.195 & 0.280 & 0.387 & 0.509 & 0.644 & 0.752 & 0.805 & 0.0897 & 0.279 \\
1996 & 0.217 & 0.291 & 0.391 & 0.507 & 0.634 & 0.738 & 0.796 & 0.0832 & 0.256 \\
2001 & 0.235 & 0.307 & 0.403 & 0.509 & 0.625 & 0.726 & 0.700 & 0.0723 & 0.252 \\
2005 & 0.252 & 0.309 & 0.398 & 0.507 & 0.623 & 0.724 & 0.689 & 0.0744 & 0.245 \\
\hline
\end{tabular}

Table 1: Evolution of concentration measures $c_{j}$, the Herfindahl-Hirsch index $h$ and the Lerner index $m$

a period of 15 years which has been characterised by intensive economic integration. The first column of the table shows the average $c_{1}$, where the average is taken over all $c_{1}$ 's which were calculated for each country and sector separately, for a specific year. There has been a substantial increase in the market share of the largest firm over the years covered in our sample. Which firms have lost in terms of the sales share? The next 7 columns of the table show the share of sales made by the 2,4,8,16,32 and 64 largest firms respectively, again averaged over all countries and industries. Consider the $c_{2}$ measure. If the largest and second largest firms together gain a total of 2.9 percentage points in sales, but the largest firm on its own gains 5.7 percentage points, this implies that the second largest firm actually lost market share. Similarly, the other $c_{j}$-measures indicate a loss of market share for large firms with the exception of the single largest firm, relative to all other firms in the economy. The decline in the concentration measures $c_{16}, c_{32}, c_{64}$ makes clear that it is small firms rather than medium-sized firms which are gaining market share. Overall, the Herfindahl-Hirsch index $h$ has significantly decreased over time.

This descriptive analysis points to a specific kind of evolution in the firm size distribution, where only the very large firms grow larger, and the rest of the distribution seems to become less skewed, somewhat more uniform, with medium size firms loosing relative market share, and smaller firms gaining relative market share. A possible cause could be that, perhaps due to the European integration process and the associated increase in the relevant market size, only the largest firms are able to compete on the truly trans-European level. This segment underwent a period of growth and consolidation to reap the benefits of production on a larger 
scale. For large to average sized firms, European integration coincided with an intensification of competition, both competition from abroad and competition from smaller firms, which were able to increase their market share during the period under consideration. The observation that the largest firms gain market share are in line with predictions of novel models of international trade with heterogeneous firms, such as Melitz (2003). The increasing market share of the smaller firms is not in line with the predictions of these models, but -leaving aside the largest firm- the trend towards a less-skewed distribution has been documented and modelled in, for example, Cabral and Mata (2003).

From a theoretical perspective, it is unclear whether and how changes in concentration should translate into changes in the market power of firms. The last column of table 1 shows the evolution of the average mark-up in all countries and sectors as measured by the Lerner-index ${ }^{5}$. The average markup has clearly declined over time in our sample.

To investigate whether these trends in concentration and market power relate to the European integration process, a small regression analysis was performed, the results of which are shown in table 2. While controlling for country-sector fixed effects, these regressions

\begin{tabular}{lccc}
\hline Dependent variable: & $c_{4}$ & $m$ & $m$ \\
\hline$\phi$ & $-0.120^{* *}$ & & $-0.221^{* * *}$ \\
& $(0.0575)$ & & $(0.0647)$ \\
$c 4$ & & $0.0677^{*}$ & \\
& & $(0.0380)$ & \\
constant & $0.628^{* * *}$ & $0.213^{* * *}$ & $0.292^{* * *}$ \\
& $(0.0198)$ & $(0.0245)$ & $(0.00733)$ \\
\hline Observations & 1045 & 1183 & 1957 \\
\hline Standard errors in parentheses. ${ }^{*} p<0.1,{ }^{* *} p<0.05,{ }^{* * *} p<0.01$ &
\end{tabular}

Table 2: Fixed effects regressions relating trade costs, market concentration and the markup

confirm the intuition that (column 1) increasing freeness of trade $\phi$ is associated with a decrease in concentration; (column 2) increasing concentration is associated with higher

\footnotetext{
${ }^{5}$ These are estimated using the method of Hall (1988).
} 
markups; and (column 3) increasing freeness of trade $\phi$ is associated with lower markups.

How and to what extent these factors offer an explanation for the declining labour share will be the subject of the remainder of this paper.

\section{Theoretical framework - Factors driving the labour share}

This section presents a theoretical framework which can be employed to understand how different factors can be expected to affect the share of labour in national income. We commence by introducing the model of Bentolila and Saint-Paul (2003) (BS henceforth). These authors show that with a constant returns to scale technology with capital and labour as sole factors of production, and allowing for labour augmenting technological change, the labour share can be written as a sole function of the readily observable capital-output ratio. BS then introduce several deviations from this framework and discuss how they are expected to shift the relationship between the labour share and the capital output ratio. We will proceed in a similar fashion. The basic framework of BS is described in section 3.1.1. The sections 3.1.2, 3.1.3 and 3.1.4 discuss respectively how capital augmenting technological change, changing intermediate goods prices, and hiring and firing costs affect the relationship between the labour share and the capital output ratio. In section 3.2.1 we add to the basic BS framework and examine possible channels through which declining trade costs and foreign competition could affect factor shares. Section 3.2.2 examines the effects of changes in market structure. The effect of skill-biased technological change is studied in section 3.2.3.

\subsection{The basic framework of Bentolila and Saint-Paul}

\subsubsection{The benchmark BS model}

To explain changes in the labour and capital share, it is necessary to make some assumptions on the technology of firms. In light of this, our starting point is the same flexible specification for technology as in BS. In their model, output $Y$ is produced using labour $L$ and capital $K$, 
with $Y=F(K, B L)$ and $F$ is sufficiently differentiable, homogeneous of the first degree and strictly increasing in both of its arguments. The parameter $B$ allows for labour augmenting technological progress. Define $l \equiv B L / K$ and $f(l) \equiv F(1, l)$, which allows to rewrite Y as $Y=F(K, B L)=K f(l)$. The capital labour ratio $k \equiv K / Y$ then can be written as $k=1 / f(l)$. Writing $p$ and $w$ for the industry price and wages, respectively, and assuming that labour is homogeneous, the labour share is

$$
L S \equiv \frac{w L}{p Y}=\frac{w l}{p B f(l)} .
$$

In the case of perfect output and labour markets, labour demand is defined by the equation of marginal cost of labour equal to marginal revenue $w^{c}=p B f^{\prime}(l)$, where $w^{c}$ stands for the competitive wage and $f^{\prime}(l)$ is the derivative of $f(l)$ with respect to its sole argument $l$.

This implies that the share of labour in the competitive case $w=w^{c}$ is simply

$$
L S=\frac{l f^{\prime}(l)}{f(l)} .
$$

As $k=1 / f(l), f$ is invertible and writing $l=h(k)=f^{-1}(k)$, the labour share can be rewritten as

$$
g(k) \equiv L S(k)=h(k) f^{\prime}(h(k)) k
$$

which defines a one-to-one relationship between the readily observable capital-output ratio $k$ and the labour share. We will use $g(k)$ to denote the labour share which has been derived under the conditions described above (such as perfect competition and excluding capital augmenting technological change) throughout this paper.

The various elements contained in this simple framework, such as capital accumulation, factor prices of labour and capital, and labour augmenting technological change do not affect this relationship between the capital-output ratio and the labour share. Changes in 
these variables change the labour share only through their effect on the capital-output ratio, suggesting that they can be adequately controlled for empirically by including (various powers of) the capital-output ratio in a regression of the labour share. What follows in the remainder of this section is a discussion of several important deviations from the base model which could offer alternative explanations for the observed change in the labour and capital share.

\subsubsection{Capital augmenting technological change}

An important stylised fact of economic growth over the last hundred years is the relative constancy of the rate of return to capital and the steady increase of wages over time. Acemoglu (2003) develops a theoretical model with a constant rate of return to capital, increasing wages and a constant labour share along the equilibrium long run growth path. In his model, firms can invest in labour and capital augmenting technological change. In the long run, firms optimally invest only in labour-augmenting innovations and the share of labour in national income is constant. After a shock, however, there might indeed be capital-augmenting technological change with the possibility of factor shares deviating from their long run equilibrium levels. These empirical and theoretical findings suggest that modelling technological change as purely labour augmenting is a reasonable approximation.

The model of Acemoglu (2003) suggests that capital augmenting technological change might occur off the steady-state growth path, and this is accompanied by changes in the factor shares. The BS model is not dynamic, but allowing for capital augmenting technological change $A$ in the production function via $Y=F(A K, B L)$ and following the same steps as in the basic BS-model, the expression for the labour share becomes

$$
L S^{A}=A k h(A k) f^{\prime}(h(A k))=g(A k) .
$$

This shows that capital augmenting technological change induces a rotation of the $L S$ - $k$ relationship. The capital-output ratio will not fully capture the effect of changes in capital 
augmenting technological change on the share of labour in national income. This result suggests that some measure of capital augmenting technological change should be included separately in a regression of the labour share to asses its impact on the share of labour in national income.

\subsubsection{Intermediary input prices}

Changes in the relative prices of additional factors of production, such as materials or energy and services, equally rotate the entire $L S-k$ schedule. Assuming $Y=F(K, B L, M)$, where $M$ stands for materials, for example, makes the labour share a function of the capital-output ratio, but also of the real price of the material input $q / p$. Assuming CES technology, BS show that the more labour and capital are substitutes (complements), the more a rise in the price of material inputs will result in a decrease (increase) of the $L S$ - $k$ schedule and thus, assuming a constant capital-output ratio, a lower (higher) labour share.

\subsubsection{Counter-cyclical labour share: adjustment costs}

Labour markets tend to be rigid, particularly in many EU Member States. If it is expensive for firms to hire and fire workers, this will affect how the labour share behaves throughout the business cycle. If firing a worker is expensive, then labour demand will remain above the frictionless level, as the real marginal cost of labour is lowered by the firing cost. This implies that, all else equal, the labour share will increase during economic downturns. The reverse also holds in presence of hiring costs and economic upturns ${ }^{6}$. This paper follows the approach of BS, controlling for adjustment costs by including the growth of employment in the labour share regression (with a negative coefficient expected).

\footnotetext{
${ }^{6}$ The relationship between the labour share and cyclicality is examined in several studies. Kydland and Prescott (1990), show that in OECD countries, the labour share is indeed countercyclical. Vermeulen (2007) corroborates this finding for France.
} 


\subsection{Additions to the Bentolila and Saint-Paul model}

\subsubsection{Economic integration and footloose firms.}

Increasing foreign competition and the risk of firms relocating to other jurisdictions in the pursuit of cost savings, are often perceived as factors which limit the scope for union wage demands, and as an important source of the downward pressure on wages and thereby, on the share of labour in national income. In this section, a small theoretical framework is developed, where the optimal union wage demand is affected by economic integration and foreign competition ${ }^{7}$.

Assume the economy consists of unionised firms in which bargaining takes place over both wages and employment (efficient bargaining). Unions aim to maximize the total wage bill $U=w L$ and take employment at the competitive wage $\bar{U}=w^{c}$ as an outside option during wage negotiations. Firms seek to maximize profits $\Pi=p Y-w L$ and take the net potential foreign profits $\bar{\Pi}$ as their outside option (threatening to relocate should negotiations fail). Although a full model describing foreign profits is not developed, $\bar{\Pi}$ can reasonably be assumed to be a function of relocation costs and foreign wages or some other measure of foreign production costs. Bargaining cooperatively, the union and the firm maximize the generalised Nash product

$$
\begin{aligned}
& \Omega=[U-\bar{U}]^{\beta}[\Pi-\bar{\Pi}]^{1-\beta} \\
& \Omega=\left[w L-w^{c} L\right]^{\beta}[(p Y-w L)-\bar{\Pi}]^{1-\beta}
\end{aligned}
$$

by setting wage and employment levels. The exponents $\beta$ and $1-\beta$ measure union and firm bargaining strength respectively. Taking the derivative with respect to wages, the bargained wage can now be expressed as the weighted average of the union outside option wage $w^{c}$ and

\footnotetext{
7 This approach is in line with Mezzetti and Dinopoulos (1991).
} 
the surplus of revenue above potential foreign profits, per worker

$$
\begin{aligned}
\frac{\partial \Omega}{\partial w} & =\beta \frac{1}{w-w^{c}}-(1-\beta) \frac{L}{p Y-w L-\bar{\Pi}} \\
w & =(1-\beta) w^{c}+\beta \frac{p Y-\bar{\Pi}}{L} .
\end{aligned}
$$

Consider two extreme cases. In the case where unions do not have any bargaining power $(\beta \rightarrow 0)$ wages are equal to the competitive wage $w^{c}$. On the other hand, if unions have full bargaining power $(\beta \rightarrow 1)$ and firms do not have an outside option $(\bar{\Pi}=0$, for example due to moving costs being prohibitively high), then unions are able to appropriate all of the operation rents $p Y$ in the form of higher wages. In this scenario, wages are equal to the operating revenue per worker $w=p Y / L$, the maximum wage which can be paid without making losses. However, if firms can credibly threaten to relocate $(\bar{\Pi}>0)$, the maximum rents the union can extract are limited to $p Y-\bar{\Pi}$. In the limiting case where foreign profits equal the operating profits of a non-unionised firm $\bar{\Pi}=p Y-w^{c} L$, the threat of delocalisation is perfect and the union can not make any wage demands above the competitive wage, irrespective of its bargaining power.

Using the expression for the bargained wage in equation (7), the following expression for the labour share in case of efficient bargaining is obtained:

$$
\begin{aligned}
L S^{U}=\frac{w L}{p Y} & =(1-\beta) w^{c} \frac{L}{p Y}+\beta \frac{p Y-\bar{\Pi}}{L} \frac{L}{p Y} \\
& =(1-\beta) g(k)+\beta\left(1-\frac{\bar{\Pi}\left(w^{F}, \phi\right)}{p Y}\right) .
\end{aligned}
$$

From equation (8) it is clear that the labour share still depends on the capital-output ratio through $k$ (as it did in the perfectly competitive case), but now the labour share also depends on the bargaining power of the union and the level of potential foreign profits, which are in turn affected by foreign wages. Transport costs do not necessarily alter the level of potential foreign profits, but they do alter whether these are relevant during wage negotiations: if transport costs 
are very high, firms do not have the choice to relocate (a part of production) and supply local customers from abroad. If firms cannot threaten to relocate, this solution coincides with BS (cf. p.14 in their article). Alternatively, if firms become more footloose (for example because trade becomes freer) or if foreign wages decline, then relocation becomes a more credible threat. This would then result in lower wages and a lower labour share. Therefore, foreign wages and a measure for the openness of trade $\phi$ are included as explanatory variables when modelling the evolution of labour and capital shares.

\subsubsection{Market structure, economic integration and markups}

If output markets are not perfectly competitive, optimal labour demand no longer follows from $w^{c}=p B f^{\prime}$. In this situation, firms hire labour up to the point where marginal costs $w^{c}$ equals marginal revenue $p[1+1 / \varepsilon]$, where $\varepsilon$ refers to the price elasticity of the demand for output of the firm. The labour demand equation then becomes $w^{c}=p B f^{\prime}[1+1 / \varepsilon]=p B f^{\prime} / m$. Here $m$ is the Lerner index, the factor by which prices exceed the marginal cost of production. The labour share then becomes

$$
L S=\frac{g(k)}{m} .
$$

Or in the case of efficient bargaining (assuming unions ignore the effect their actions might have on the price setting behaviour of firms):

$$
L S^{m}=\frac{w l}{p B f}=(1-\beta) \frac{g(k)}{m(\phi, \rho)}+\beta\left(1-\frac{\bar{\Pi}\left(w^{F}, \phi\right)}{p Y}\right) .
$$

In the workhorse Dixit-Stiglitz model of monopolistic competition markups are constant and solely depend on the parameter controlling the price elasticity of substitution between varieties. Despite the many advantages of the Dixit-Stiglitz framework, the fact that markups are constant has long been recognised as a rather unrealistic property of this model. Since then, various models of international trade have been developed where markups are time variant and depend 
on, for example, trade openness ( $\phi$ ) (see Ottaviano, Tabuchi, and Thisse, 2002), or the extent of concentration $(\rho)$ in an industry (Melitz and Ottaviano, 2008). Following from this, in this paper, the markup $m$ is assumed to be a function of trade openness and concentration, with $m_{\phi}<0$ and $m_{\rho}>0$. The reverse effects also hold for the labour share, which - at least as far as the effect works through changes in the markup - is increasing in the openness of trade and decreasing in the level of concentration. It is worth noting that even in this simple model the predicted effect of trade on the labour share is ambiguous. Freer trade simultaneously increases the outside options of firms (leading to a lower labour share) while also decreasing their market power (increasing the labour share).

\subsubsection{Skill-biased technological change and skill-upgrading}

One last possible deviation from the standard BS model we consider, is the case of skillbiased technological change and skill-upgrading. Many technological innovations allow firms to reduce the use of low-skilled labour in favour of both capital and high-skilled labour. As noted by Berman, Bound, and Machin (1998), many studies find that the increase in the skill-premium which has been observed in developed and many undeveloped countries, can be attributed to skill-biased technological change. Krusell, Ohanian, Ríos-Rull, and Violante (2000) show that if capital and high-skilled labour are complements in production, which seems highly likely, an increasing stock of capital equipment would lead to the observed skill-bias technological change, by increasing the marginal product and return to skilled labour, and decreasing the marginal product and return to unskilled labour. Monfort, Vandenbussche, and Forlani (2008) find that increased exposure to low-wage competition has lead firms to switch their product mix towards high-quality products, resulting in a higher ratio of skilled to unskilled workers and higher capital intensity. As such, the switch towards more capital and skill intensive production may be caused by increasing trade openness.

The two-layer CES production function of Sato (1967), which is also considered in Krusell, Ohanian, Ríos-Rull, and Violante (2000) and Arpaia, Pérez, and Pichelmann (2009), is a 
convenient choice for the analysis of skill-biased technological change. Writing $L_{s}$ and $L_{u}$ for the input of skilled and unskilled labour in production, this production function is defined as

$$
\begin{aligned}
& Y=\left[\mu\left(B_{u} L_{u}\right)^{\frac{\sigma-1}{\sigma}}+(1-\mu) X^{\frac{\sigma-1}{\sigma}}\right]^{\frac{\sigma}{\sigma-1}} \\
& X=\left[\lambda(A K)^{\frac{\eta-1}{\eta}}+(1-\lambda)\left(B_{s} L_{s}\right)^{\frac{\eta-1}{\eta}}\right]^{\frac{\eta}{\eta-1}}
\end{aligned}
$$

where $\mu$ and $\lambda$ are share parameters. The elasticity of substitution between skilled and unskilled labour is given by $\frac{1}{1-\sigma}$, the elasticity of substitution between capital and skilled labour equals $\frac{1}{1-\eta}$. Capital is more complementary with skilled labour compared to unskilled labour if $\sigma>\eta$.

Given this specification of technology, Arpaia, Pérez, and Pichelmann (2009) show that the labour share can be written as a sole function of three input-ratio's: $\frac{L_{s}}{L_{u}}$, measuring the skill-intensity; $\frac{A K}{B_{u} L_{u}}$ measuring the capital-to-unskilled labour intensity, and $\frac{A K}{B_{s} L_{s}}$ measuring the capital-to-skilled labour intensity. For the case of capital-skill complementarity $(\sigma>\eta)$, these authors show that the following factors lead to a decrease in the labour share:

- A decrease in the capital-to-skilled ratio, provided there is some substitution between capital and skilled labour $(\eta>0)$.

- An increase in the ratio of skilled-to-unskilled labour, provided that skilled and unskilled labour are highly substitutable $(\sigma>1)$.

- An increase in the ratio of capital-to-unskilled labour, if $\sigma>1$.

- An increase in A, capital augmenting technological change, if capital is highly substitutable with skilled labour $(\eta>1)$.

Given these predictions, the input-ratio's and a measure for capital augmenting technological change will be added as explanatory variables in the analysis of the labour share in the empirical section. 


\section{Empirical estimation}

This section considers the evolution of the labour share in a selection of 8 major manufacturing sectors ${ }^{8}$ in 12 EU15 member states ${ }^{9}$, for the years 1970-2005. The number of countries, sectors and years which are included in the sample is limited mainly by the availability of data on the capital stock. In specifications including the measure of trade openness $\phi$, the number of observations is further reduced because the trade data which is needed for the calculation of $\phi$ is only available for the years 1980-2001 in the CEPII database.

Before assessing how the explanatory variables suggested in the previous section affect the labour share, we consider one potentially highly relevant and simple explanation for the observe decline in the labour share: changes in the relative weight of industries with an otherwise constant labour share in the total economy. Since the time span under consideration is rather long (35 years), major compositional shifts such as the declining importance of the manufacturing sector and the increasing weight of services in the economy could greatly affect the aggregate labour share even if the labour share is constant, but different, within the manufacturing and services sector. Appendix A.2 considers such compositional effects, but it is found that changes within industries are more relevant to explaining changes in the labour share for the countries and time period under consideration. Similarly, it is found that changes in firm sizes can not explain the observed changes in the labour share.

The theoretical considerations outlined in section 3.1 suggest to augment the basic relationship

$$
\log \left(L S_{i t}\right)=\beta_{0}+\beta_{1} \log \left(K_{i t} / Y_{i t}\right)+\varepsilon_{i t},
$$

which relates the labour share in sector $i$ and year $t$ to its capital-output ratio, with several explanatory variables which cause deviations from the $L S-k$ relationship. The richest specification

\footnotetext{
${ }^{8}$ These are the following 2-digit and combined NACE sectors 20, 21-22, 24, 25, 26, 27-28, 29, 30-33 and 34-35. Some of the sectors had to be aggregated due to data constraints.

${ }^{9}$ The countries are Austria, Belgium, Denmark, Spain, Finland, France, the United Kingdom, Germany, Ireland, Italy, the Netherlands and Portugal.
} 
which will be considered takes the following form

$$
\begin{aligned}
\log \left(L S_{i t}\right) & =\beta_{0}+\beta_{1} \log \left(K_{i t} / Y_{i t}\right)+\beta_{2} \log \left(A_{i t}\right)+\beta_{3} \log \left(p_{i t}^{I} / p_{i t}\right) \\
& +\beta_{4} \log \left(L_{s, i t} / L_{u, i t}\right)+\beta_{5} \log \left(K_{i t} / L_{u, i t}\right)+\beta_{6} \log \left(K_{i t} / L_{s, i t}\right) \\
& +\beta_{7} \Delta \log \left(L_{i t}\right)+\beta_{8} \log \left(w_{i t}^{F}\right)+\beta_{9} \phi_{i t}^{\prime}+\beta_{10} m_{i t}+\varepsilon_{i t}
\end{aligned}
$$

where, for each year $t$ and sector $i, L S_{i t}$ represents the labour share, $K_{i t} / Y_{i t}$ is the capitaloutput ratio, $A_{i t}$ is a measure of capital augmenting technological change, $p_{i t}^{I} / p_{i t}$ is the relative price of intermediary inputs, and $\frac{L_{s}}{L_{u}}, \frac{K}{L_{u}}$, and $\frac{K}{L_{s}}$ are various input-ratio's. $\Delta \log \left(L_{i t}\right)$ represents employment growth, $w_{i t}^{F}$ is the foreign wage. $\phi_{i t}^{\prime}$ and $m_{i t}$ are, respectively, measures of trade openness and the market power of firms.

The following variables will be used as proxies of the quantities contained in equation (11) (detailed variable definitions are given in the appendix). logcapoutput is the ratio of a capitalstock index and real gross added value. $\log T F P$ is the logarithm of the total factor productivity contained in the EUKLEMS dataset. Given the fact that labour augmenting technological change is accounted for by its effect on the capital-output ratio, changes in TFP should capture capital augmenting technological change. Total factor productivity is measured as an index, however, and the size of the coefficient on logTFP therefore can not straightforwardly be interpreted. loginterprice is the price of intermediate inputs relative to the gross value added price. The input ratio logskillshare corresponds to the ratio's of hours worked by high-skilled workers relative to the total number of hours worked by low and medium skilled workers. logcapskilled is the ratio of the capital index relative to the number of hours worked by skilled labour. logcapunskilled similarly expresses the capital stock with respect to the number of hours worked by low and medium skilled labour. dlogemp is the growth of employment. lerner is the Lerner-index. logwageEU is the logarithm of the average wage in all countries except the country under consideration. 
Table 3 shows the result of estimating equation (11), using OLS with country $\times$ industry fixed effects, year dummies, and country-specific time-trends. These time-trends have been included to control for the omission of variables with country-specific trends, such as inflation. Identification of the estimated effects therefore is mainly obtained from differences in the evolution of the labour share (and the covariates) between different sectors in each country. This makes the reported results rather robust. The specifications in table 3 do not include the

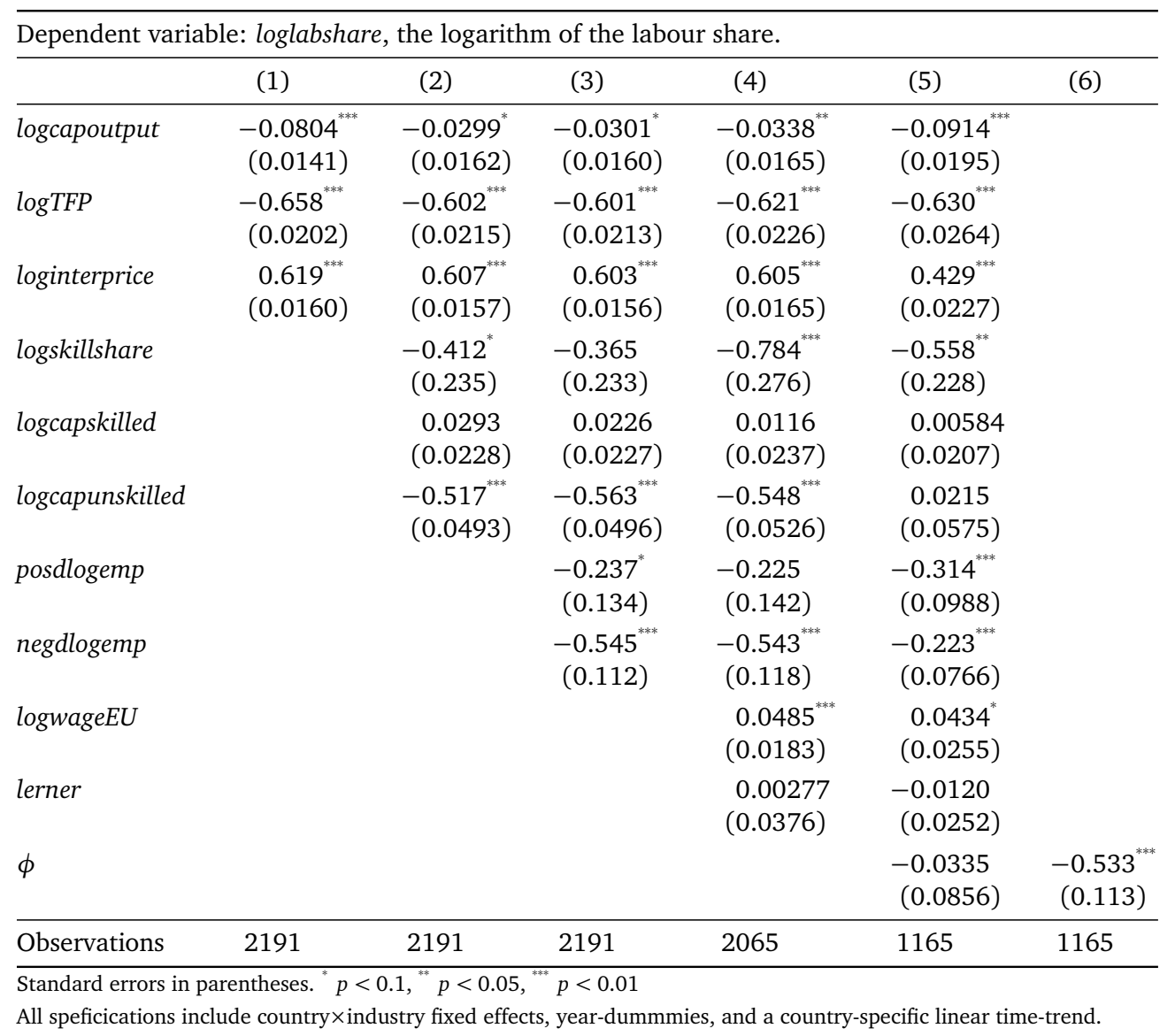

Table 3: Estimation of the basic equation and extensions

$c_{j}$ concentration measures as explanatory variables, as these are available only for the years 1991-2004 and therefore including them would substantially reduce the sample size.

Column (1) shows the results when including some important covariates suggested by BS. All coefficients have the expected sign and are significant. The fact that the coefficients on 
logcapoutput and $\operatorname{logTFP}$ have the same sign is as expected under the assumptions of BS. The coefficient on loginterprice is large and highly significant, which is in contrast to the small and imprecisely estimated effect measured by BS, which use the relative price of oil. A partial explanation for this could be the fact that we include the price of all intermediate inputs.

The specification reported in column (2) includes the various input ratio's intended to capture the effects of skill-biased technological change and changes in the relative supply of skilled versus unskilled labour. Although the coefficient on the capital-to-skilled-labour ratio is insignificant, the sign of the coefficients on all three variables coincides with the predictions made in section 3.2.3, for the case where capital is less substitutable (or complementary) with high-skilled labour compared to unskilled labour. The ratio of capital-index to the number of hours worked by unskilled labour seems to have has the largest impact on labour share, but it is important to note that the size and significance of the reported coefficients is not informative as to whether these variables had an economically significant effect on the labour share and thus can explain a significant share of the change therein. We will later consider standardised coefficients which consider the economic rather than statistical significance.

Column (3) adds changes in log-employment, which corresponds to percent changes in employment. Positive and negative changes are included separately through posdlogemp and negdlogemp. ${ }^{10}$ It is important to take into account that the coefficient on these variables still reflects the effect of a positive change in the corresponding variable. The fact that the coefficient on both variables is negative reveals that the labour share is below its equilibrium level when employment is rising, and above its optimal level when employment is falling. This is indicative of adjustment costs. The fact that the coefficient on negative employment changes is significantly larger in absolute value suggests that firing costs are more important than hiring costs, which seems plausible.

\footnotetext{
${ }^{10}$ For positive changes: posdlogemp $=\Delta$ logemp if $\Delta$ logemp $>0$ and posdlogemp $=0$ if $\Delta$ logemp $<=0$. For negative changes: negdlogemp $=\Delta \operatorname{logemp}$ if $\Delta \operatorname{logem} p<0$ and posdlogemp $=0$ if $\Delta \operatorname{logemp}>=0$.
} 
Column (4) of table 3 is our preferred specification. It controls for foreign wages and the industry level Lerner index, which serve as proxies for foreign low-wage competition and the market power of firms, respectively. A limited number of observations is lost for which one or both of these additional variables is not available. Higher foreign wages are predicted to increase union leverage and therefore the labour share, and a positive and significant coefficient on foreign wages is indeed found. It is likely, however, that the coefficient on foreign wages captures various other channels through which foreign and local wages are correlated in an open economy context. The Lerner index measure of market power is not found to have had a significant impact on the labour share.

Column (5) includes $\phi$ as an explanatory variable. Since trade flows are only available from 1980 to 2001 and are missing for some country/sector combinations, the number of observations is almost halved. As the trade freeness measure $\phi$ has been meticulously constructed using long time series on country-sector level trade flows, the fact that the estimated effect of $\phi$ is not statistically different from zero might come as a disappointment. Two consideration should be made, however. Firstly, the effect of $\phi$ is actually estimated rather precisely: although it can not confidently be stated that the effect of freer trade is positive or negative, it is known with a high degree of certainty that the coefficient is relatively close to zero. Secondly, the effect of $\phi$ reported in column (5) is, in a sense, residual. It should be interpreted as the effect of trade liberalisation which affects the labour share through channels which are not taken into account by the inclusion of all other variables contained in the regression.

The fact that the effect of the capital-to-unskilled labour ratio becomes small and insignificant in column (5) is not due to the introduction of $\phi$. When not controlling for $\phi$, but retaining only the 1165 observations for which this variable is available, the effect of logcapskilled is small and insignificant as well. The change in the coefficient on logcapskilled between specification (4) and (5) therefore rather reflects that the effect is not constant across the sample. The 
fact that the other coefficients do not show such major changes in column (5), despite the significantly smaller subsample used therein, illustrates the robustness of these estimates.

It might be interesting to know the effect of trade liberalisation while allowing it to operate in various ways, not fixing any of these channels by including them as covariates in a regression. The theoretical considerations presented in the last section suggest that the sign of the effect of $\phi$ without controlling for covariates can not be readily predicted. Whereas freer trade is expected to make firms more footloose and thus limit the bargaining strength of unions which leads to a lower labour share, freer trade is simultaneously predicted to increase the labour share if freer trade implies lower markups, for example. Moreover, as argued in section 3.2.3, trade liberalisation may lead to skill-upgrading, which in turn may affect the labour share. The regression reported in the last column (6) of table 3 shows this unconditional effect of $\phi$, although - as in all specifications reported in the table - time and country-specific time trends have been included. Without controlling for concurrent changes in other variables, the effect of $\phi$ on the labour share is large and significant even when including year-dummies and country-specific linear time trends. This suggests that trade liberalisation indeed impacted on the labour share. The fact that the effect of trade openness becomes small and insignificant when conditioning on several covariates (column (5)), suggests that the channels through which the effect of $\phi$ operates are adequately modelled in this rich specification.

The results reported in table 3 show whether the variables under consideration had a significant effect on the labour share in a purely statistical sense. An important remaining question is whether these variables are able to explain a large share of the observed changes in the labour share. Table 4 tries to answer this question by showing standardised coefficients. These standardised coefficients express by how many standard deviations the dependent variable is predicted to change after a one standard deviation change in an independent variable, keeping all other covariates constant. As the typical movement of the dependent variable is one standard deviation, a small number therefore implies that the independent 


\begin{tabular}{lccc}
\hline & Lower bound & Estimate & Upper bound \\
\hline For the coefficients in column (4) & & \\
\hline logcapoutput & -0.35 & -0.18 & -0.01 \\
logTFP & -0.87 & -0.81 & -0.75 \\
loginterprice & 0.55 & 0.58 & 0.61 \\
posdlogemp & -0.04 & -0.02 & 0 \\
negdlogemp & -0.08 & -0.06 & -0.03 \\
lerner & -0.04 & 0 & 0.04 \\
logwageEU & 0.02 & 0.07 & 0.13 \\
logskillshare & -0.37 & -0.22 & -0.07 \\
logcapskilled & -0.17 & 0.06 & 0.29 \\
logcapunskilled & -1.44 & -1.21 & -0.98 \\
\hline For a selection of coefficients in column (5) & \\
\hline logskillshare & -0.52 & -0.29 & -0.06 \\
logcapskilled & -0.31 & 0.05 & 0.41 \\
logcapunskilled & -0.25 & 0.06 & 0.37 \\
logwageEU & -0.01 & 0.08 & 0.18 \\
lerner & -0.06 & -0.01 & 0.04 \\
$\phi$ & -0.09 & -0.02 & 0.06 \\
\hline For the coefficient on $\phi$ in column $(6)$ & -0.25 & -0.14 \\
\hline$\phi$ & -0.35 & & \\
\hline
\end{tabular}

Table 4: Standardised coefficients and 95-percent confidence interval, for some of the regressions reported in table 3

variable under consideration can not be a sufficient explanation for the observed change in the dependent variable (again, the ceteris-paribus condition applies). Contrary to common practice, the standardised coefficient is reported alongside an upper and lower boundary of an 95-percent confidence interval. The standardised coefficients in table 3 clearly show that it is unlikely that ceteris-paribus changes in the trade freeness, changes in market power, or foreign low-wage competition had a major impact on the labour share. The effect of these variables is dwarfed by the effect of changes in TFP (capturing capital-augmenting technological change) or the relative price of intermediates.

Even when considering changes in the trade freeness measure $\phi$, while not keeping any other variable fixed except for year dummies and country-specific time trends, the estimated 
effect remains relatively limited (see column (6) of table 3): without controlling for any co-movement of $\phi$ with other variables, a one standard deviation in $\phi$ is estimated to account only for about a quarter standard deviation in the labour share.

Table 5 considers a last specification where the Lerner index is replaced by the $c_{32}$ concentration measure as an explanatory variable. ${ }^{11}$ This comes at the considerable cost of restricting the sample to the years 1991-2001. Although some coefficients become insignificant for this shorter

\begin{tabular}{lc}
\hline & loglabshare \\
\hline logcapoutput & 0.0488 \\
& $(0.0859)$ \\
logTFP & $-0.472^{* * *}$ \\
& $(0.0890)$ \\
loginterprice & $0.642^{* * *}$ \\
& $(0.0337)$ \\
logskillshare & 0.535 \\
& $(0.438)$ \\
logcapskilled & 0.0573 \\
& $(0.0433)$ \\
logcapunskilled & $-0.372^{* * *}$ \\
& $(0.130)$ \\
posdlogemp & 0.166 \\
& $(0.128)$ \\
negdlogemp & $-0.399^{* * *}$ \\
& $(0.111)$ \\
logwageEU & $0.140^{* *}$ \\
& $(0.0598)$ \\
phi & $-0.383^{* * *}$ \\
& $(0.141)$ \\
(mean) c32 & $-0.0927^{* *}$ \\
& $(0.0508)$ \\
\hline Observations & 443 \\
\hline Standard errors in parentheses \\
* $p<0.1,{ }^{* *} p<0.05,{ }^{* * *} p<0.01$
\end{tabular}

Table 5: The estimated effect of several covariates on the labour share. The inclusion of the $c 32$ concentration measure restricts the analysis to the years 1991-2001.

\footnotetext{
${ }^{11}$ In unreported regressions it was found that the effect of $c_{j}$ becomes more negative and more significant when larger values of $j$ are considered. The Lerner index was dropped as an explanatory variable since including both the Lerner index and the concentration measure caused both variables to become insignificant.
} 
subsample, none of the results obtained before are significantly altered. As with the Lerner index, calculation of standardised coefficients indicate that changes in market concentration are unlikely ${ }^{12}$ to have caused a significant share of the observed decline in the share of income accruing to labour.

\section{Conclusion}

This paper, using a number of approaches, examined the evolution of the labour share in the EU and considered several potential explanations. After noting that compositional effects alone can not explain the observed changes in the labour share, some possible determinants of the labour share were derived from the framework of Bentolila and Saint-Paul (2003). These authors show that, under specific conditions including the assumption of CRS technology with labour augmenting technological change, the share of national income accruing to labour moves along a (non-linear) relationship with the capital-output ratio. Factors such as the presence of capital augmenting technological change, changes in the prices of intermediary goods, and the presence of labour adjustment costs lead to deviations from this relationship. The paper extends the model of Bentolila and Saint-Paul (2003) by considering the effect on the labour share of changes in the market power of firms, market concentration, foreign wages, skill-biased technological change, and trade openness.

Most predictions of the basic Bentolila and Saint-Paul (2003) model and the extensions were found to hold in a sample of 9 major industrial sectors in $12 \mathrm{EU}$ countries for the years 1970-2005, using data from the EUKLEMS dataset. Overall, ceteris-paribus changes in the relative price of intermediates, capital augmenting technological change, and the increasing ratio of skilled-to-unskilled workers are estimated to have had a large and significant impact on the labour share.

\footnotetext{
${ }^{12}$ The standardised coefficient on $c_{32}$ equals -0.11 , with a 95-percent confidence interval of $[-0.23,0.01]$.
} 
Substantially smaller effects are found for the other explanatory variables. Lower foreign wages decrease the local labour share, which is in line with the theory that foreign competition limits the possibility of non-market wage setting by unions. Furthermore, industry concentration measures are constructed using firm level data and it emerges that industries with higher concentration levels are associated with lower labour shares, as predicted by theory. Firm markups were estimated using the Hall method but were found not to have a statistically significant impact on the labour share. Similarly, a measure of trade openness was calculated using detailed sector-level trade data for each country from the CEPII database, but no significant effect was found. Moreover, the confidence interval of the standardised coefficients of these variables, expressing how well these variables can explain the observed overall change in the labour share, indicates that these variables are highly unlikely to have caused the observed decline in the labour share.

Importantly, the effects considered above are derived under the assumption that all other variables which are considered are kept constant. As trade integration may affect the labour share through several of these channels, the effect of trade openness was also considered both without controlling for explanatory variables. The results suggest that, without controlling for simultaneous changes in variables which affect the labour share, and including the effects which trade openness might have had on any other variables affecting the labour share, changes in trade openness can account for a maximum of about one third of the observed decline in the labour share.

Overall, the findings suggest that the European integration process has lowered the labour share by a small amount. In any case the effect of economic integration and changes in the market structure is quite limited when compared to the effects of technological change, skill-upgrading and changes in the relative prices of intermediary goods. 


\section{References}

Acemoglu, D. (2003): "Labor- and capital-augmenting technical change," Journal of the European Economic Association, 1(1), 1-37.

Arpaia, A., E. PÉrez, And K. Pichelmann (2009): “Understanding labour income share dynamics in Europe," MPRA Paper 15649, University Library of Munich, Germany.

Bentolila, S., AND G. Saint-Paul (2003): "Explaining movements in the labor share," Contributions to Macroeconomics, 3(1), 1-31.

Berman, E., J. Bound, AND S. MACHIN (1998): "Implications of Skill-Biased Technological Change: International Evidence," Quarterly Journal of Economics, 113(4), 1245-1279.

Blanchard, O. (1997): "The medium run," Brookings Papers on Economic Activity, 2, 89-158.

Budd, J., J. Konings, And M. Slaughter (2005): "International profit sharing in multinational firms," Review of Economics and Statistics, 87, 73-84.

CABral, L., AND J. Mata (2003): "On the Evolution of the Firm Size Distribution: Facts and Theory," American Economic Review, 93(4), 1075-1090.

De Serres, A., S. Scarpetta, And C. De La Maisonneuve (2001): "Falling wage shares in Europe and the United States: How important is aggregation bias," Empirica, 28, 375-400.

GuscinA, A. (2007): "Effects of globalization on labor's share in national income," IMF working paper, 06294.

HAll, R. (1988): "The relation between price and marginal cost in US industry," Journal of Political Economy, 96(5), 921-947.

HEAD, K., AND J. RIES (2001): "Increasing returns versus national product differentiation as an explanation for the pattern of US-Canada trade," American Economic Review, 94(4), 858-876.

Huizinga, H., AND L. LAEven (2007): "International profit shifting within European multinationals," CEPR Discussion Paper, 6048.

Hutchinson, J., AND D. Persyn (2009): "Globalisation, concentration and footloose firms: in search of the main cause of the declining labour share," LICOS Discussion Papers, 22909.

Jaumotte, J., AND I. Tytell (2007): "How has the globalization of labor affected the labour share in advanced countries?," IMF working paper, 07298.

Kaldor, N. (1963): "Capital accumulation and economic growth," in Proceedings of a conference held by the International Economics Association, ed. by F. Lutz, and D.C.Hague. Macmillan, London.

KlAPPER, L., L. LAEVEN, AND R. RAJAN (2006): "Entry regulation as a barrier to entrepreneurship," Journal of Financial Economics, 82, 591-629.

Konings, J., P. VAn Cayseele, And F. WARZynski (2001): “The Dynamics of Industrial Markups: Using Firm Level Panel Data in Two Small Open Economics to Assess whether Competition Policies Matter," International Journal of Industrial Organisation, 19(5), 841-859.

Krusell, P., L. E. Ohanian, J.-V. Ríos-Rull, And G. L. Violante (2000): “Capital-Skill Complementarity and Inequality: A Macroeconomic Analysis," Econometrica, 68(5), 1029-1054.

Kydland, F., And E. Prescott (1990): "Business-Cycles: Real facts and a monetary myth," Federal Reserve Bank of Minneapolis Quarterly Review, 154(2), 3-18.

Lyons, B., C. Matraves, AND P. Moffatt (2001): "Industrial concentration and market integration in the European Union," Economica, 68, 1-26.

Mayer, T., R. Paillacar, And S. Zignago (2008): "CEPII Trade, Production and Bilateral Protection Database: Explanatory Notes," Available at http://www.cepii.fr/anglaisgraph/bdd/TradeProd.

Melitz, M. (2003): "The Impact of Trade on Intra-Industry Reallocations and Aggregate Industry Productivity," Econometrica, 71(6), 1695-1725.

Melitz, M., AND G. Ottaviano (2008): “Market size, trade and productivity," Review of Economic Studies, 75(1), 295-316.

Meyler, A. (2001): "Profit margins in the euro area. A macro-economic perspective," Central Bank of Ireland.

Mezzetti, C., AND E. Dinopoulos (1991): "Domestic unionization and import competition," Journal of International Economics, 31, 79-100.

Monfort, P., H. VAndenbussche, And E. Forlani (2008): "Skill-upgrading in European textiles resulting from 
trade with China: firm-level evidence," in Essays in Memory of Michel Norro, ed. by A. Nyembwe. Université Catholique de Louvain, Louvain-la-Neuve.

Moral, E., AND V. Gernre (2007): "Labour share developments in the euro area," Banco De Espana Economic Bulletin, pp. 97-110.

Mueller, D. (1996): “Lessons from the United States' antitrust history," International Journal of Industrial Organization, 14(4), 414-445.

Ottaviano, G., T. TABuchi, AND T. Thisse (2002): "Agglomeration and trade revisited," International Economic Review, 43, 409-436.

SATo, K. (1967): "A two-level constant-elasticity-of-substitution production function," The Review of Economic Studies, 34(2), 201-218.

Vermeulen, P. (2007): "Can adjustment costs explain the variability and counter-cyclicality of the labour share at the firm and aggregate level?," ECB working paper, 772. 


\section{A. Appendices}

\section{A.1. Variable definitions}

- labshare: nominal labour compensation / nominal value added.

- TFP: Measure of sector-level TFP provided in the EUKLEMS dataset.

- capoutput: capital stock index / real gross value added.

- interprice: intermediate input prices / gross value added price.

- skillshare: the ratio of hours worked by high-skilled workers relative to the total number of hours worked by low and medium skilled workers. The skill levels are defined in the EUKLEMS dataset.

- capskilled: the ratio of the capital index relative to the number of hours worked by skilled labour.

- skillshare: the ratio of the capital index relative to the number of hours worked by low and medium skilled labour.

- posdlogemp: growth of employment, if positive; 0 otherwise.

- negdlogemp: growth of employment, if negative; 0 otherwise.

- wageEU: (Total compensation in EU countries excluding own) / (Total employment in EU countries excluding own).

- $\phi$ : See section 2.1 .

- lerner: the industry level mark-up estimated using the Hall method.

- $c_{j}$ : concentration ratio: sum of sales of the $j$ largest firms in an industry, relative to the total sales in that industry. Or more formally, $c_{k}=\sum_{i=1}^{k} s_{i} / \sum_{i=1}^{n} s_{i}$, with $s_{i}$ the sales of firm $i$ and $n$ the total number of firms in the industry under consideration. Firms have been sorted by sales such that $s_{i}>s_{i+1}$. 


\section{A.2. Decomposition of changes in the labour share}

In this section, the relative importance of compositional changes versus changes within the composing units is examined more formally using the decomposition of De Serres, Scarpetta, and De La Maisonneuve (2001). It is found that changes in the sectoral composition alone can not explain the observed change in the labour share.

De Serres, Scarpetta, and De La Maisonneuve (2001) these authors write the aggregate labour share of a multi-sector economy in some year $t$ as the sum of the value-added weighted labour share of each sector $i$ :

$$
L S_{t}=\frac{\sum_{i=1}^{k} \operatorname{comp}_{i, t}}{\sum_{i=1}^{k} v a_{i, t}}=\sum_{i=1}^{k} \frac{v a_{i, t}}{\sum_{i}^{k} v a_{i, t}} \frac{\operatorname{comp}_{i, t}}{v a_{i, t}}=\sum_{i=1}^{k} \omega_{i, t} L S_{i, t}
$$

where, for sector $i$ in year $t, \operatorname{comp}_{i, t}$ is the labour compensation of employees and the selfemployed, $v a_{i, t}$ is value added, $\omega_{i, t}$ is the share of the sector in the total economy value-added, and $L S_{i, t}$ is the labour share. Differentiating over time, the change in the aggregate labour share can be split into two components;

$$
\Delta L S_{t}=\sum_{i=1}^{k} L S_{i, t} \Delta \omega_{i, t}+\sum_{i=1}^{k} \omega_{i, t-1} \Delta L S_{i, t} .
$$

The first term shows the effect of changes in the weight of sectors, offering an indication of the quantitative importance of the 'compositional effect' in changes of the aggregate labour share. The second term is the weighted sum of the change in labour shares within each sector, the 'within effect'.

Figure 3 shows the decomposition of the change in the aggregate labour share of the EU15, using data for the EU15 from the EUKLEMS database, decomposing the change in the labour share in changes within 46 2-digit NACE sectors (within effect), and changes between them (compositional effect). These 46 sectors cover the entire private sector of the EU. The bars in each figure show the decomposition of the growth in the labour share in the decade preceding the indicated year.

Appendix A.3 shows the sectoral decomposition of the movement of the labour share separately for all member states in our sample. What emerges is that there are large differences between countries in the relative importance of within and compositional factors as explanatory factors of the changing labour share. The compositional component has tended to decrease the 


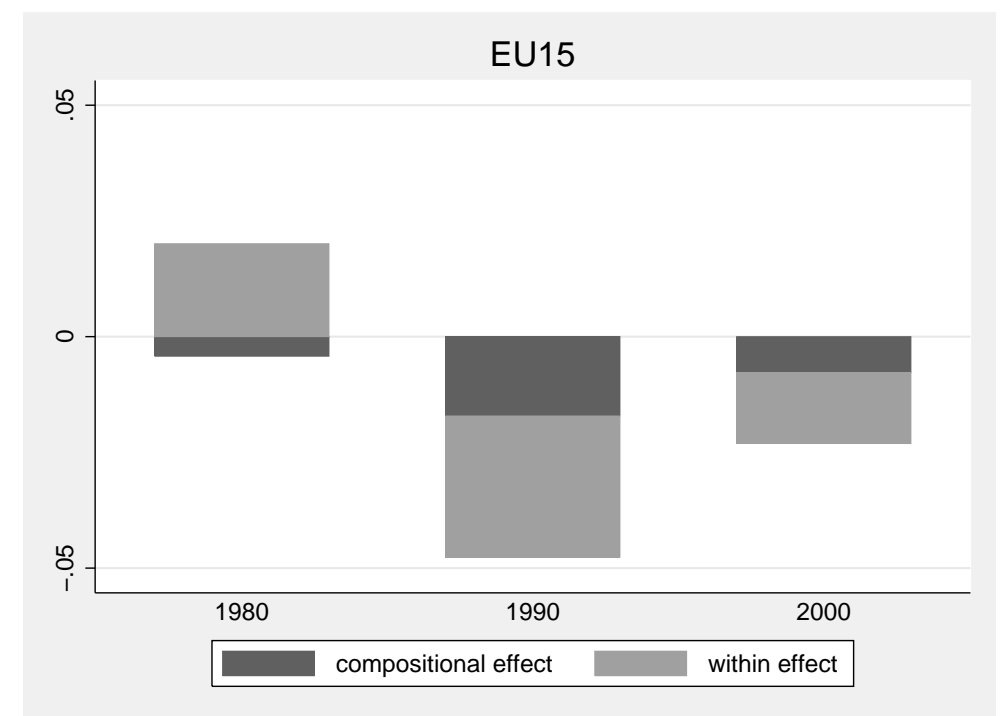

Figure 3: Decomposition of the evolution in the labour share of the EU15.

aggregate labour share in most countries over the time period under consideration, with the notable exception of Portugal. The within-sector changes have been an important driver of the labour share, although the direction of the influence has been less clear cut.

We can therefore confirm the finding of De Serres, Scarpetta, and De La Maisonneuve (2001) (who use a much smaller set of countries), that changes in the sectoral composition can help explain a significant part of the decline in the labour share on the aggregate level. As can be seen from figure 5, the 'within effect' for the EU15 clearly outweighs the 'compositional effect', however, and therefore the changing sectoral composition is far from a complete explanation for the observed decline in the labour share.

Changes in the relative importance of sectors may not be the only type of compositional change in the economy which affect the evolution of the labour share. If the firm size distribution was affected by the European integration process, for example, and larger firms have a different labour share ${ }^{13}$ we may expect to find significant inter-firm compositional effects. Figure 4 presents the results of applying the same decomposition method to a sample of 46015 Belgian firms for the years 1998-2006. The firm level data come from the commercial database Belfirst of Bureau Van Dijk. Overall, the change in the relative size of firms (a 'compositional effect') appears to have had a negative influence on the aggregate labour share over the period under consideration, which was also the case for the sectoral decomposition. On average, the labour shares of individual firms increased significantly in the years 2001-2002,

\footnotetext{
${ }^{13}$ We will argue below that this might be the case if large firms have more market power, or are more footloose, for example.
} 


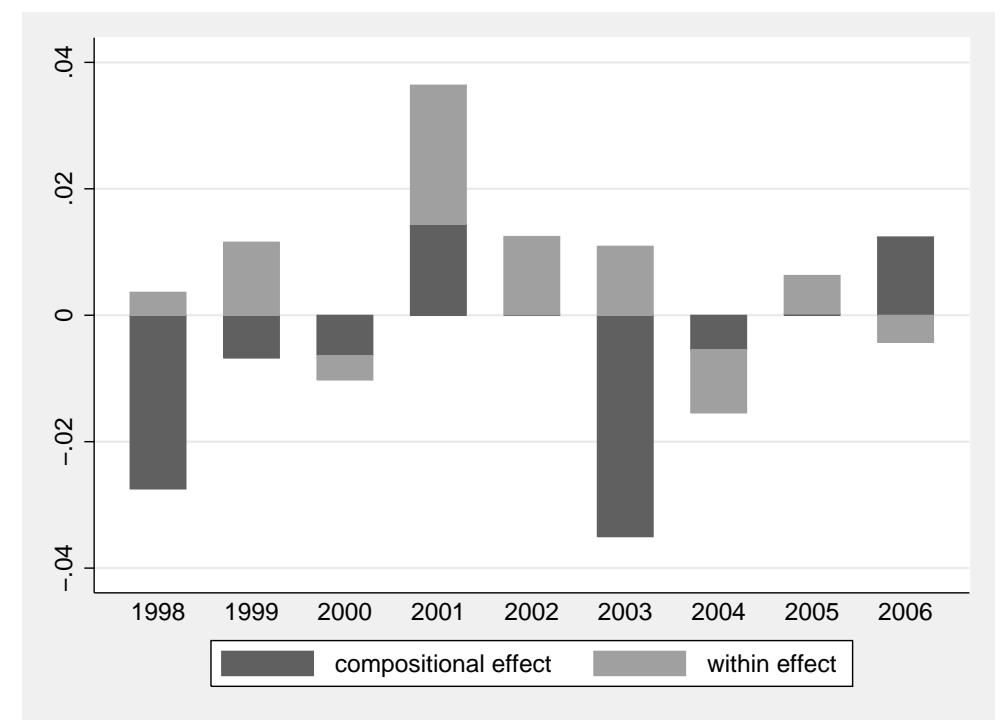

Figure 4: Decomposition of changes in the labour share in within firm changes and changes in the relative importance of firms in the overall economy.

during the economic downturn in that period, suggesting that cyclicality may be an important factor in explaining changes in factor shares.

The significant size and ambiguous direction of the within component, both at the firm and sector level, suggest that a significant share of the observed variance of factor shares cannot be explained by compositional effects, and that there might be other fundamental factors driving factor shares. Moreover, the decomposition methodology remains silent on the causes of the differences in the initial (or long-run equilibrium) levels of the labour share in the units under consideration.

A.3. The sectoral decomposition of changes in the labour share in several EU member states 

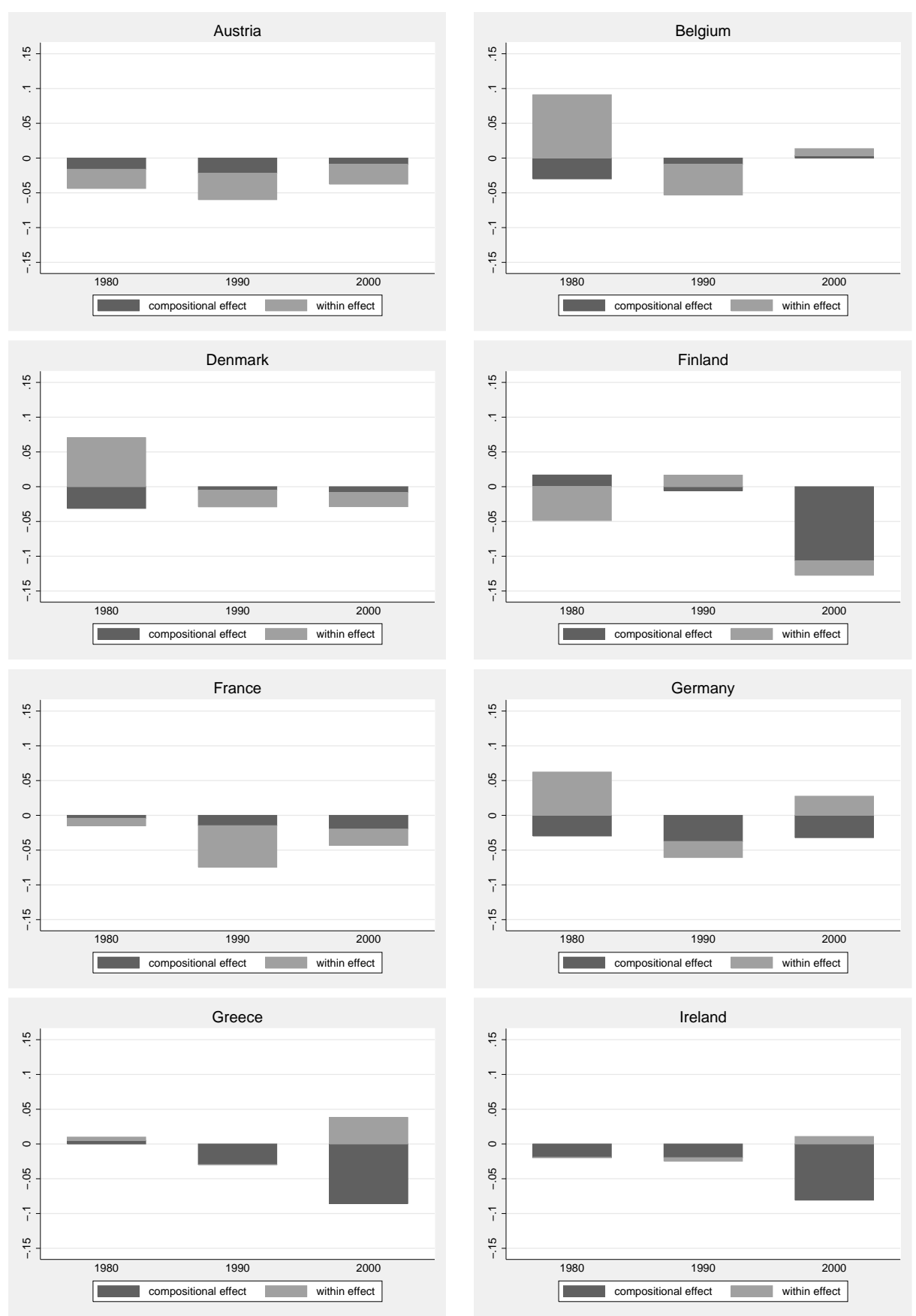

Figure 5: Decomposition of changes in the labour share in within sector changes and changes in the relative importance of sectors in the overall economy. The bars for both effects are stacked if they have the same sign. The length of a bar gives the change (attributable to that component), during the decade ending at the indicated year. 

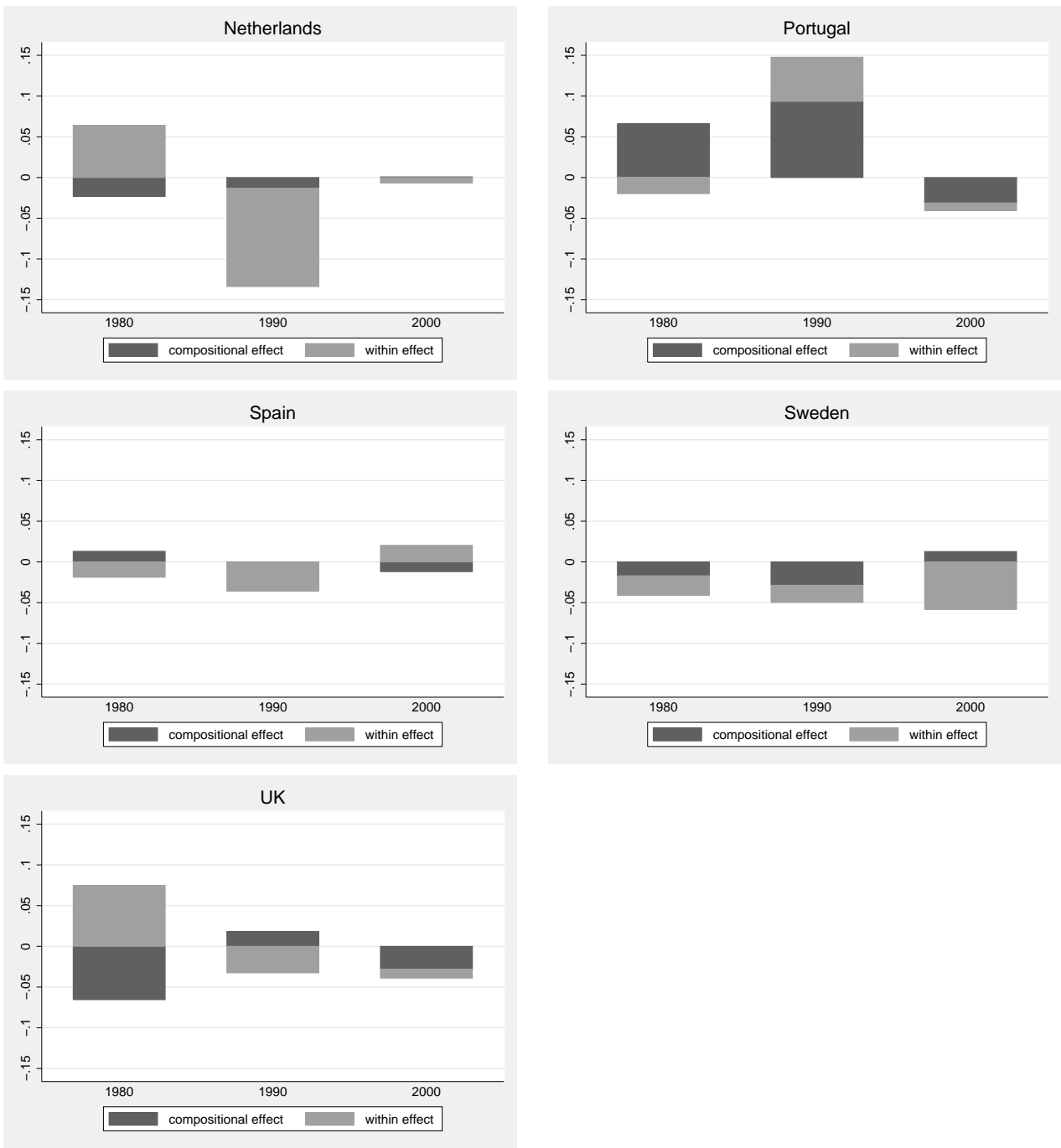

Figure 6: ... continued from last page: decomposition of changes in the labour share in within sector changes and changes in the relative importance of sectors in the overall economy. 